\title{
AN AIRPLANE WITH UNCONVENTIONALLY PLACED PROPELLER POWER UNITS
}

\author{
Jan Červinka, Robert KulháneK*, ZDenĚK PÁtek \\ VZLÚ a.s. - Aerospace Research and Test Establishment, Beranových 130, Prague, Czech Republic \\ * corresponding author: kulhanek@vzlu.cz
}

ABstRact. The significance of the influence of operating propellers on the aircraft aerodynamic characteristics is well-known. Wind tunnel testing of an airplane model with operating propellers is a complex task regarding the required similarity of the full-scale and the model case. Matching sufficient similarity in axial and rotational velocities in the propeller slipstream is the primordial condition for the global aerodynamic similarity of the windtunnel testing. An example of the model power units with related devices is presented. Examples of the wind tunnel testing results illustrate the extent of the propeller influence on aerodynamic characteristics of an aircraft of unconventional configuration with power units positioned at the fuselage afterbody.

KEYwORDS: windtunnel testing; propeller slipstream; T-tail aircraft; propeller simulation.

\section{INTRODUCTION}

The simulation of the propeller effects is an important part of the wind tunnel testing of an airplane. Both the importance and the complexity of the simulation are given by the fact that the aerodynamic phenomena connected with a propeller are very complex including complex interactions between the propeller(s) and the airframe.

\section{REVIEW OF CURRENT RESEARCH}

The first scientific studies treating the influence of the propeller on the aerodynamics and flight mechanics of an airplane were published as early as in the thirties of the last century, in relationship with the increasing power of the installed engines and the spreading of the multi-engine aircraft [1-3]. Especially, Millikan's study [4] is considered as a principal fundament with many other authors continuing and developing it in specific areas (as for example [5]). These works are based mainly on the empirical expressions considering the power-on propeller downwash and the tail in the slipstream; these expressions are developed from the results of the wind tunnel testing. The importance of the mutual position of the propeller with its slipstream and the wing and the horizontal tailplane was perceived as well as the influence of the sense of the rotation of the propeller. But the above mentioned classical studies are focused on the conventional configuration of an airplane, i.e., the tractor propellers positioned ahead of the leading edge of the wing and the horizontal tailplane on the fuselage or in the proximity of the fuselage. There are many other studies focused on the propeller-wing interference (even in the last period, for example [6, 7]), but this phenomenon is not the main topic of this paper.

The studies devoted to the propeller influence have appeared during the decades, but none of them specifically focused on the studied configuration. The global survey of the available literature sources up to 1985 is given in 8 . This survey contains abstracts and excerptions from 121 sources and confirms that the unconventional configurations have been out of the interest of the most studies. The main interest of the recent studies consisted in the critical case with one engine inoperative on a twin-engine aircraft (for example [9 11]), i.e., the aim is the examination of the influence of propeller and its slipstream especially on the directional stability and controllability.

The twin-engine aircraft with aft placed propellers are rare but have been existing and successfully flying. Their designers undoubtedly had to cope with the problems of the influence of the propellers, but the details about their aerodynamics and flight mechanics do not seem to be available in open literature. One exemption is [12] which includes among others data concerning configuration with pusher propellers on the wing but it is configuration is totally different from the studied configuration with pusher power units on the rear of the fuselage.

The presented study intends to fill the gap in the understanding of the influence of the propellers on the unconventional twin-engine configuration of an airplane that is characterized by the two propellers on the rear of the fuselage and by the T-tail. It was supposed that the influence on the wing was marginal but influence on the tail and thus longitudinal and directional stability and controllability could be significant.

As was published in [11, 13, for the conventional twin-engine configuration, the yawing moment with one engine inoperative is not a simple thrust of the operative engine multiplied by its arm to the centre of gravity. In addition to it, there is a complex aerodynamic interaction, especially between the propeller slipstream and the fuselage and primarily the vertical tailplane that causes that the total yawing moment is approximately 50 percent higher. 


\section{Motivation}

The importance of the influence of the operating propeller power units on aircraft aerodynamic characteristics is well-known. The propeller units create both direct effects caused by the forces acting directly at the propeller (thrust, normal force, torque moment) and indirect effects caused by the significant aerodynamic influence on the aircraft and on the flow circumventing the airframe. This influence is caused primarily by the interaction of the propeller slipstream with other parts of the aircraft.

It is also evident that the influence depends essentially on the power output of the power unit; the higher power output, the higher direct forces but also the higher "indirect" aerodynamic influence as the strength of the slipstream is related to the forces created at the propeller. The power is often usefully relative to the size of the aircraft, the relation can be conveniently expressed for example using power-tomass ratio of an aircraft. The effects of the propeller on the wing or on the whole aircraft are well-described in the case of the conventional propeller-driven aircraft configuration, i.e., in the case of a single-engine aircraft with propeller on the nose of the fuselage and in the case of a multi-engine aeroplane with propellers in front of the leading edge of the wing.

But the experimental results for the unconventional configuration with propellers positioned on the rear part of the fuselage behind the wing and in the proximity of the tail surfaces have not been found in the available literature sources. As the both direct and indirect propeller effects influence not only the aircraft aerodynamics but also its flight dynamics behaviour as one of main consequences, therefore the simulation of the propeller effects at wind tunnel testing of an airplane is very important. Especially the influence on aircraft stability and controllability can be crucial.

\section{THEORY OF SIMILARITY}

\subsection{Propeller efFECTS}

The most significant direct and indirect effects are as follows.

\section{(1.) Direct effects}

- Thrust in the axis of the propeller

- Normal force in the plane of rotation of the propeller

- Torque moment of the propeller

(2.) Indirect effects of the propeller slipstream

- Effect on the moments of the wing

- Effect on the lift of the wing

- Effect on the downwash and the crossflow at the tail unit

- Effect on the dynamic pressure at the tail unit

The simulation of the propeller slipstream for a constant-speed propeller requires matching both the slipstream axial velocity-to-airspeed and the slipstream rotational velocity-to-airspeed ratios. But to match these both ratios over the entire range of the aircraft lift coefficients would require an adjustable pitch propeller, in ideal case adjustable "in flight" during testing run and that is a very challenging issue. However, a satisfactory approximation of the real slipstream can be accomplished with a single setting of a propeller pitch (or very limited number of settings) over a large part of the lift coefficients, so manually "on ground" adjustable propeller is sufficiently adequate for the wind tunnel testing.

From propeller momentum theory, it can be found that the axial velocity ratio can be matched with a propeller of a scale diameter. The rotational velocity ratio can be matched with a geometrically similar propeller operating at the proper advance ratio.

To match required similarity in the thrust and torque, the equality of the full-scale $\mathrm{T}_{\mathrm{cFS}}$ and the model $\mathrm{T}_{\mathrm{cM}}$ and of the $\mathrm{Q}_{\mathrm{cFS}}$ and $\mathrm{Q}_{\mathrm{cM}}$ coefficients shall be matched.

It is possible to deduce, if the full-scale and model propellers are geometrically similar, that for a given propeller advance ratio (identical for both the fullscale and model propellers $\mathrm{J}_{\mathrm{M}}=\mathrm{J}_{\mathrm{F}}$ ), the correct similarity of the thrust is preserved when $\mathrm{T}_{\mathrm{cM}}=$ $\mathrm{T}_{\mathrm{cFS}}$. In a similar manner, the similarity of the torque moment is preserved when $\mathrm{Q}_{\mathrm{cM}}=\mathrm{Q}_{\mathrm{cFS}}$ see example Pope [14] for the deduction that we present in the brief form.

The conditions of similarity suppose that the geometrically similar propellers, at a given advance ratio, have identical $\mathrm{C}_{\mathrm{TFS}}$ and $\mathrm{C}_{\mathrm{TM}}$ (and analogically $\mathrm{C}_{\mathrm{QFS}}$ and $\mathrm{C}_{\mathrm{QM}}$ ) coefficients, which is not exactly matched in reality because of very different propeller Reynolds numbers and different propeller Mach numbers. The model to the full-scale Reynolds numbers ratio is given by the ratio of the wind tunnel flow velocity to the flight airspeed multiplied by the geometric scale factor, the Mach numbers ratio is given by the ratio of the wind tunnel flow velocity to the flight airspeed. The partial correction can be achieved by model propeller design, the propeller is not designed in practice as exactly geometrically similar to the full-scale propeller; it keeps the correct scale diameter and the number of blades, whereas the airfoil sections of the blades are different, taking into account the differences of the Reynolds and Mach numbers. The result of the proper model propeller design is that the differences in the thrust and torque coefficients between the fullscale and the model propellers are negligible from the practical point of view if the low-speed testing is performed in the linear region of the propeller characteristics (i.e., in the linear regions of $\mathrm{C}_{\mathrm{T}}$ vs $\mathrm{J}$ and $\mathrm{C}_{\mathrm{Q}}$ vs J curves).

In practice, there is limited amount of regimes of the flight to be tested, the maximum power unit (take-off) regime and the cruise regime are usually examined. It is possible to design the propeller model in a way 


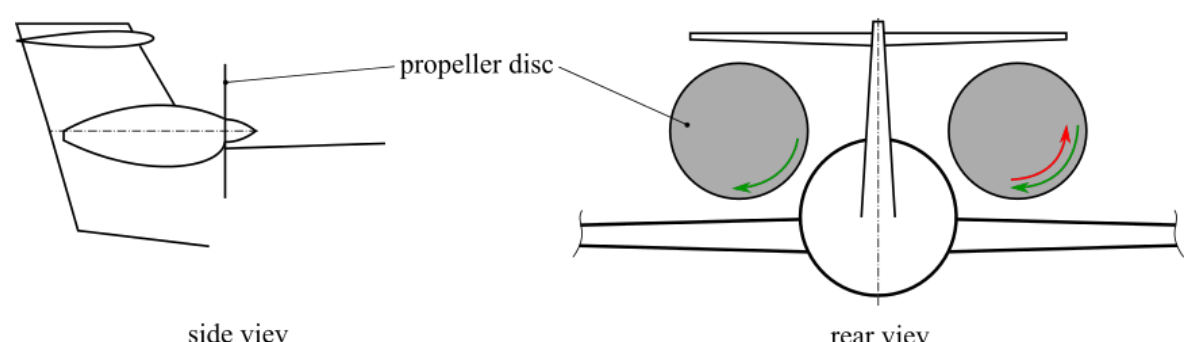

Figure 1. Schematic sketch of tested configuration.

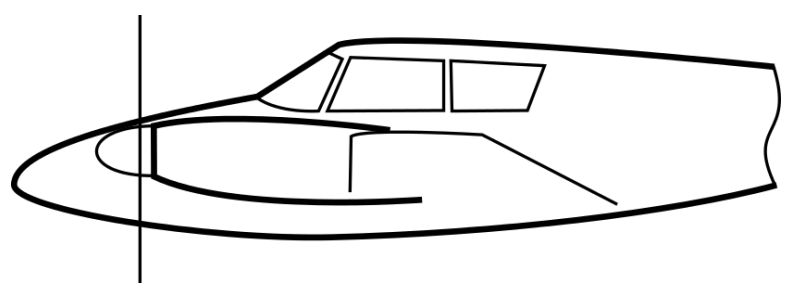

Figure 2. Schematic sketch of REF. 1 configuration.

that it is aerodynamically sufficiently similar at one selected blade incidence to the full-scale propeller in these regimes. With the appropriately designed the propeller, the thrust coefficient can be matched exactly and, simultaneously, the torque coefficient can be matched with the discrepancy of several percent, i.e., within acceptable limits.

\subsection{Model And Testing Device}

An experimental wind tunnel testing was performed with a generic model of a small low-wing monoplane with T-tail and with two propellers positioned at the rear part of the fuselage. To emphasize the effects connected with the propeller, the propeller diameter was relatively big and the thrust coefficient of the power units relatively high. The propellers could rotate either in the identically oriented senses (the both clockwise viewed from the rear, the green arrow in Figure 1 either on in counter-rotating mode (the left propeller clockwise, the right propeller counterclockwise).

The model propellers were driven by electric motors built in the models of the engine nacelles. The model propeller has a diameter of $0.4 \mathrm{~m}$ and was powered by electronic engines with a maximum power of $16 \mathrm{~kW}$ at $11000 \mathrm{rpm}$. This value of the advance ratio corresponds to the take-off regime.

The results of the unconventional configuration were compared with one conventional configuration and one unconventional configuration of a different type. The conventional airplane is a small low-wing monoplane with a conventional tail and two propellers placed in front of the wing. The layout of this configuration can be seen in Figure 2 and the wind tunnel testing is described in reference [15]. The second one, the unconventional configuration is a low-wing monoplane

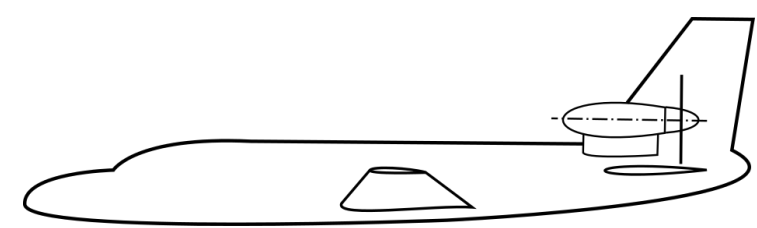

FiguRE 3. Schematic sketch of REF. 2 configuration.

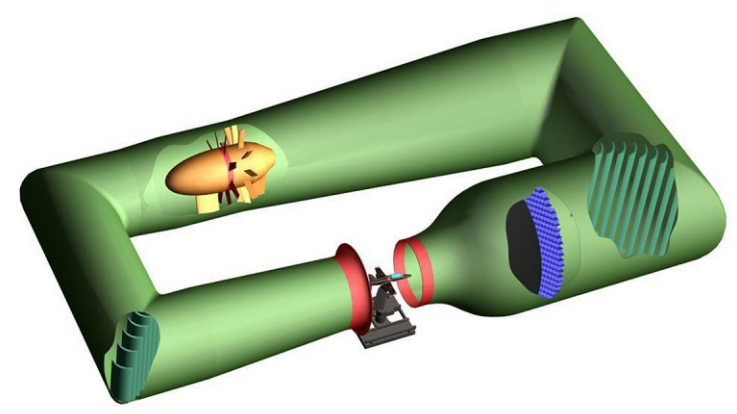

Figure 4. Wind tunnel.

from reference [16. The layout of this configuration is similar but with engines placed above the horizontal tail unit. The sketch of this configuration can be seen in Figure 3 .

The tests were carried out in a low-speed closed circut atmospheric wind tunnel operaited by VZLU Aerospace Research and Test Establishment in Prague. The wind tunnel has the following main characteristics.

- Circural test section of $3 \mathrm{~m}$.

- Maximum velocity $75 \mathrm{~m} / \mathrm{s}$ (with ventilation), $90 \mathrm{~m} / \mathrm{s}$ (without ventilation)

- Characteristic turbulence intensity $0.3 \%$.

The wind tunnel sketch can be seen in Figure 4

\section{Results}

The results of the wind tunnel testing are presented in Figure 5 to Figure 9. The testing with operating propellers was performed at Reynolds number 900,000 (related to the wing mean aerodynamic chord). The thrust coefficient of one propeller Tc was kept constant regardless the angle of attack of the airplane model. 


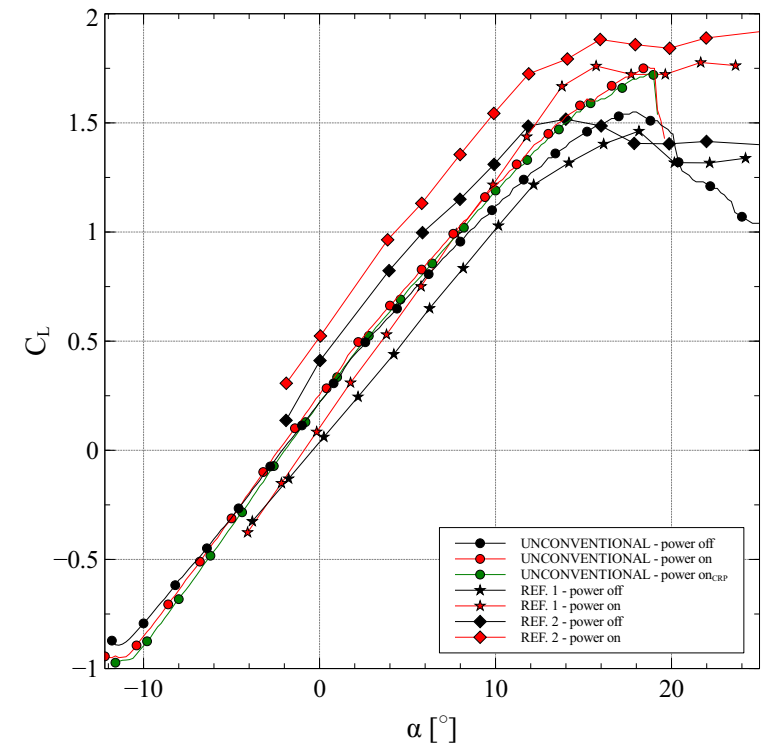

Figure 5. Lift curves.

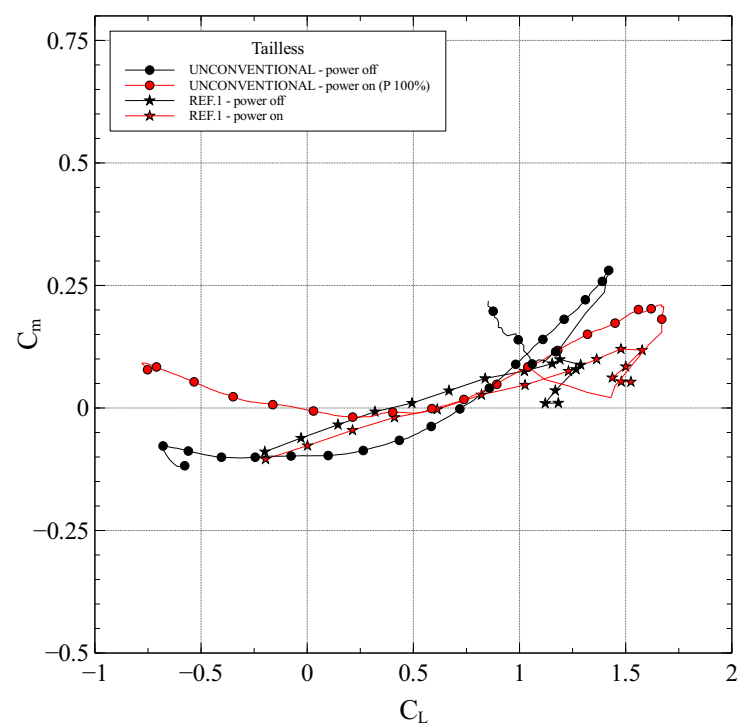

Figure 6. Moment curves of tailless aircraft.

The results are compared with the conventional configuration (in the figure legend marked as REF. 1) and some of them with unconventional one (REF. 2).

As was published in [11, 13] for the conventional twin-engine configuration, the yawing moment with one engine inoperative is not a simple product of the thrust of the operative engine multiplied by its arm to the centre of gravity. In addition to it, there is a complex aerodynamic interaction, especially between the propeller slipstream and the fuselage and, primarily, between the slipstream and the vertical tailplane that causes that the total yawing moment is approximately 50 percent higher. This phenomenon yields important influence on the directional stability and controllability. The influence of one engine operative on the studied configuration reveals to be more complex as it

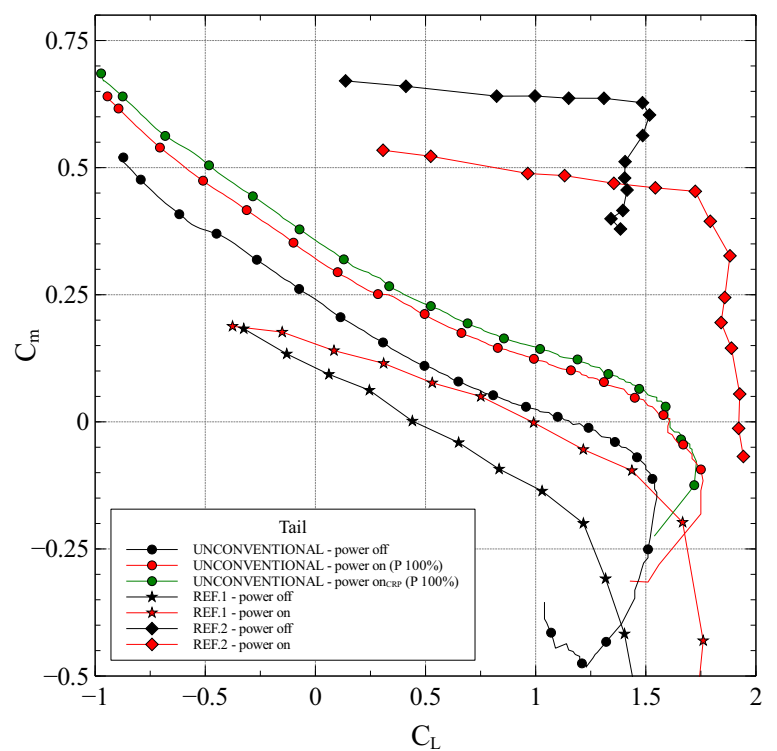

FiguRE 7. Moment curves of complete aircraft.

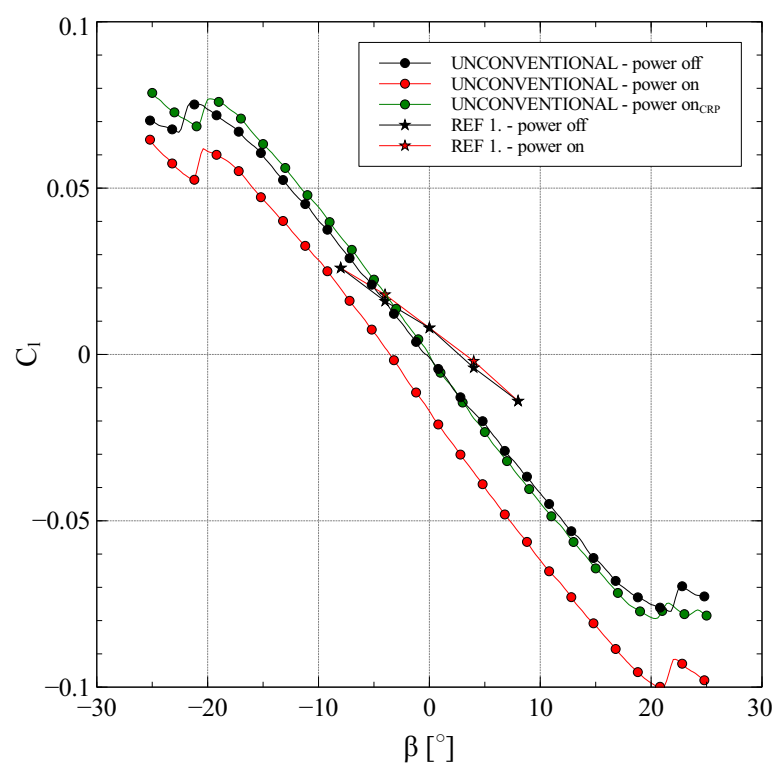

FiguRE 8. Rolling moment coefficient.

surprisingly strongly depends on the sense of rotation of the propeller.

With the propeller blades moving from-up-to-down in the proximity of the vertical tailplane (i.e., clockwise turning on the left engine), the result is of a similar nature as in the case of the conventional configuration: the resulting yawing moment is approximately 1.25 higher than the product of the engine thrust and its arm. With the opposite sense of rotation (i.e., counter-clockwise on the left engine), the yawing moment diminish to nearly zero, i.e., the aerodynamic interference practically wipes out the moment created by the engine thrust multiplied by its arm. It seems to be a significant finding. However, with possible but in practice probably limited impact. It implies that 


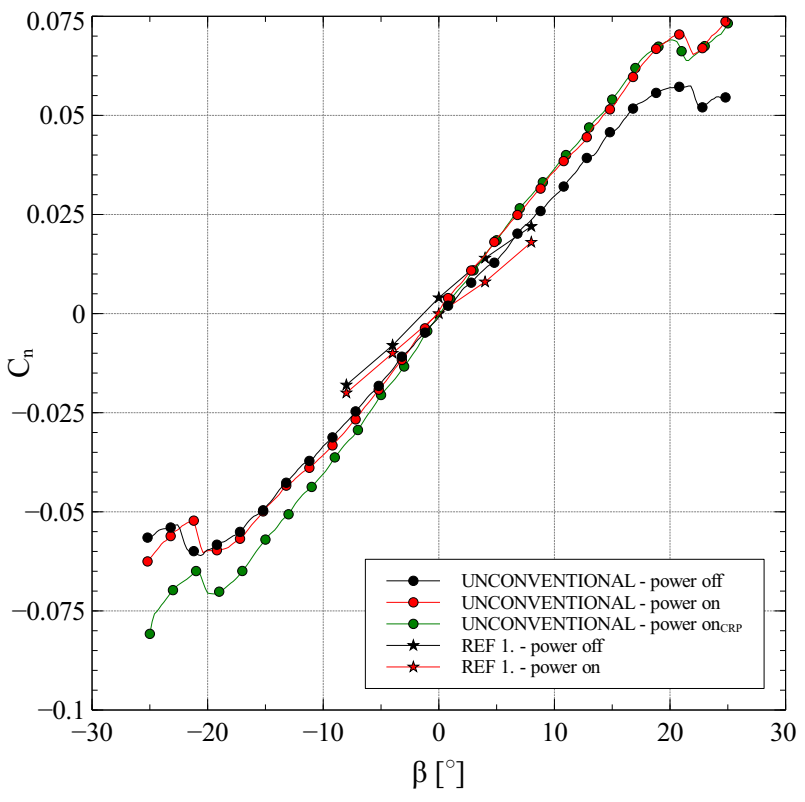

Figure 9. Yawing moment coefficient.

the desirable reduction of the vertical tailplane and rudder could be possible but the real exploitation of it would require the opposite senses of rotation of the engines and thus two different versions of the engine with different gearboxes.

From the point of view of the flow physics, it indicates a strong interaction between the propeller and the vertical tailplane and (maybe) the wing wake but the exact nature of it remains to be clarified in detail. Set of flow visualizations on the rear part of the fuselage and on the vertical tailplane were performed but without registering any significant difference.

\section{DisCussion}

\subsection{The InfluenCE OF PROPELLERS ON LIFT}

A detectable difference is observed between the two cases of the propeller rotation. The slope of the both lift curves is almost identical, but $\mathrm{C}_{\mathrm{L} 0}$ for the counterrotating propellers is slightly lower, $\triangle \mathrm{C}_{\mathrm{L} 0} \approx-0.02$. The explanation is probably in the flow over the horizontal tailplane, as its right side was influenced mainly by the counterclockwise rotating propeller which rather decreases the angle of attack. In general, the position of the propeller above and under the horizontal surface, does not significantly change slope of the lift curve.

The influence of the propellers placed on the wing (REF. 1) is more significant. The increment $\triangle \mathrm{C}_{\mathrm{L} 0} \approx$ 0.1 is much higher than in the case of the non conventional configuration. Higher increment of the lift coefficient is due to the fact that the propeller slipstream increases the local velocity around small portion of the wing behind the propeller. The explanation for the higher lift curve slope of the conventional configuration can also be found in this phenomenon.

\subsection{The INFLUENCE OF PROPELlERS ON STATIC LONGITUDINAL STABILITY OF AN AIRPLANE WITHOUT HORIZONTAL TAIL SURFACE}

The direct effect of the thrust is removed from the pitching moment characteristics by the positioning the centre of gravity in the thrust line. The reference points have identical longitudinal distance relative to the mean aerodynamic cord for all tested configuration. It is evident that the presence of the power units has the stabilizing effect. The neutral point moves backward by approximately 8 percent of the mean aerodynamic cord for unconventional configuration and by approximately 1 percent for the REF. 1 one. The conventional configuration has the nose down pitching moment. The explanation is that the increased velocity over the part of the wing magnify the wing pitchig moment. The significant effect of the power units on the static stability of the unconventional configuration can be explained as a stabilizing effect of the propeller normal force. The pitching moment of the unconventional configuration differs around zero angle of attack where the propeller normal force supposed to be zero it can be resumed that this nose-up pitchig moment has to be product of changes in flowfield near pylons of the nacelle.

\subsection{The INFLUENCE OF PROPELLERS ON STATIC LONGITUDINAL STABILITY OF A WHOLE AIRPLANE}

The influence of the rotating propellers on the horizontal tailplane is pronounced as a longitudinal destabilization of the airplane. The neutral point moved forward by approximately 5 percent of the mean aerodynamic chord with the propellers rotating in the identical senses, and by approximately 1 percent with the counter-rotating propellers. With respect to the fact that the propellers have an opposite influence than in the case of the aircraft without the horizontal taill, it seems possible to deduce that there is a very significant influence of the propellers on the horizontal tail, regardless the geometrical fact that the horizontal tailplane is positioned high above the propellers and only slightly behind the plane of the propeller discs. The propellers create such changes in the flowfield that it consequently led to the decreasing of the angle of attack of the horizontal tailplane and thus to the diminution of its lift (with respect to the convention that positive lift was directed "upwards"). This influence is even more pronounced for the counter-rotating propellers.

The almost constant nose-up pitching moment is produced by the increased velocity under the horizontal tail surface. A simillar phenomenon was also reported in reference [16. In that study, the aircraft with the power units placed above the horizontal tail surface was tested in the wind tunnel. This configuration is marked as REF. 2 in Figure 7 and it can be observed that the power units have stabilizing effect 
and add nose-down pitching moment. The neutral point moves backward by approximately 3 percent of the mean aerodynamic chord.

The rotating propellers of the conventional configuration have adverse effect on the longitudinal static stability. The neutral point moved forward by approximately 12 percent of the mean aerodynamic chord. It can be seen that the power effect change the static margin without tail minimally so it can be deduced that the propeller slipsteam changes the downwash behind the wing and the horizontal stabilizer less effectively.

\subsection{The INFLUENCE OF PROPELLERS ON STATIC LATERAL-DIRECTIONAL STABILITY}

\subsubsection{ROLL}

The rotation of the propellers increases the "lateral stability", i.e., increases the absolute value of the derivative of the rolling moment with respect to the sideslip angle. The increase is approximately 16 percent with both propellers rotating clockwise and 12 percent with counter-rotating propellers. The probable reason is the difference between the force components at the left and the right propellers discs created as a result of combination of the angle of attack and the sideslip angle. This phenomenon is slightly suppressed by the counter-rotating propellers. The reaction torque moment of the clockwise rotating propellers also causes the negative rolling moment at the zero sideslip angle. The moment is relatively high as its value corresponds to the sideslip of 4 degrees.

The placement of the propeller on aircraft wing has a negligible effect on the lateral stability. The shift of the rolling moment coefficient at the zero sideslip angle is caused by a wind tunnel airstream misalignment according to reference [15.

\subsubsection{YAW}

The influence of the propellers on the derivative of the yawing moment with respect to the sideslip angle is also highly pronounced, and the propeller operation significantly increases its value also in this case. The increase is approximately 17 percent with the propellers rotating clockwise and 23 percent with the counter-rotating propellers. The reasons are higher dynamic pressure on the vertical tail unit and the side force component at the propeller discs created as a result of sideslip.

The absolute value of the derivative of the yawing moment with respect to the sideslip angle decreased by about 6 percent. This can be caused by the interaction of the propeller slipstream with the vertical tail unit. This effect is more pronounced with the increased sideslip angle.

\subsection{The influence of the type OF ROTATION OF THE PROPELLERS}

As resulted from the previous analysis, the type of the rotation of the propellers is not negligible, but its significance is moderate. Nevertheless, the differences between the propellers rotating in the identical senses and the counter-rotating propellers are registered in all of the studied relations. Probably the most important from the point of view of the flying qualities is the difference in the static longitudinal stability where the counter-rotating propellers manifested even more destabilizing effect than the propellers rotating in the identical senses. On the contrary, the counter-rotating propellers do not naturally cause the aerodynamic asymmetries at the zero sideslip angle, they are registered mainly at the roll moment with the propellers rotating in the identical senses.

\section{SUMMARY}

The wind tunnel testing enabled estimation of the influence of propellers positioned at the rear part of the airplane on the principal aerodynamic and stability characteristics of an airplane. In spite of the position of the propellers at the afterbody of the fuselage and thus limited influence on the wing, the effect on longitudinal and lateral stability is significant as the tailplanes even at T-configuration are evidently affected to a high extent.

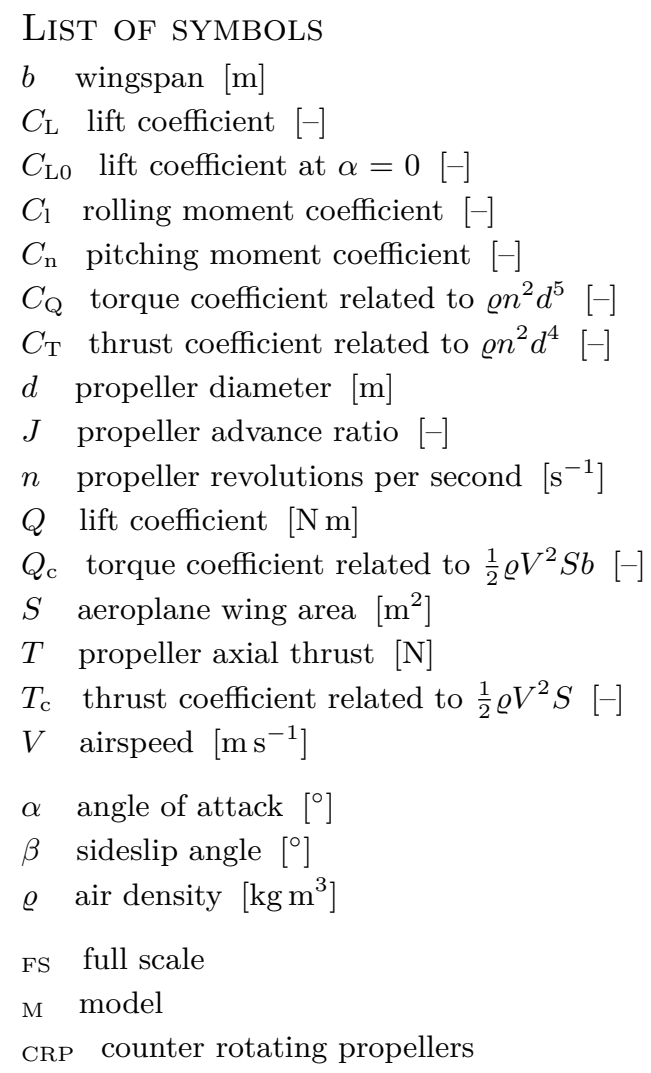

\section{REFERENCES}

[1] B. H. Luftschraubenstrahl und Längsstabilität. Luftfahrtforschung, Vol. 11, p. 202 - 206,München and Berlin 1935, 1935. 
[2] S. J. Effect of Propeller Slipstream on Wing and Tail. NACA TM 874, Washington, 1938.

[3] R. P. Aérodynamique expérimentale. Librairie polytechnique Ch. Béranger, Paris and Lille, 1945.

[4] M. C. B. The Influence of Running Propellers on Airplane Characteristics. Journal of the Aeronautical Sciences, Vol. 7, no.3, pp. 85 - 103, 1940.

[5] S. J. H. A. Bell R. W. Some Aspects of the Effects of Propeller Operation on the Static Longitudinal Stability of an Airplane. Thesis. California Institute of Technology, Pasadena, 1941.

[6] H. J. W. C. Kuhn R. E. Wind-Tunnel Investigation of Effect of Propeller Slipstreams on Aerodynamic Characteristics of a Wing Equipped with a 50-Percent-Chord Sliding flap and a 30-Percent-Chord Slotted Flap. NACA TN 3918, Washigton, 1957.

[7] V. L. L. M. Propeller Wing Aerodynamic Interference. Delft University of Technology, Delft, 2005.

[8] v. L. E. Miley S. J. Propeller Propulsion System Integration, State of Technology Survey. NASA CR-3982, 1985.

[9] E. M. E. Van Rooyen R. S. Assessment of propeller influence on lateral-directional stability of multiengine aircraft. Journal of Aircraft, Vol. 18, No. 5, pp. 364-371, 1981.
[10] S. R. Schroijen M.J.T. Propeller slipstream effects on directional aircraft control with one engine inoperative. AIAA-2007-1046, 2007.

[11] S. R. Schroijen M. J. T., Veldhuis L. L. M. Propeller Slipstream Investigation Using the Fokker F27 Wind Tunnel Modle with Flaps Deflected. ICAS Congress, Anchorage, Congress Proceedings, pp. 360-1 - 360.14, 2008.

[12] D. S. G. Propeller. Airframe Aerodynamic Interference on Twin Engine Aircraft. ICAS Congress, Harrogate, Congress Proceedings, pp. 123.1 - 123.10, 2000.

[13] S. R. Schroijen M. J. T., Veldhuis L. L. M. Propeller Empennage Interaction Effects on Vertical Tail Design of Multiengine Aircraft. Journal of Aircraft, Vol. 47, No.4, pp. 1133-1140 DOI: 10.2514/1.46707, 2010.

[14] P. A. Barlow J. B., Rae W. H. Low-Speed Wind Tunnel Testing, 3rd Edition. Wiley-Interscience, 1999.

[15] J. P. S. Muruin P. Fink, J. Charles C. Smith. A wind-tunnel investigation of static longitudinal and lateral characteristics of a full-scale mockup of a light twing-engine airplane. National aeronautics and space administration,Washington D.C., 1971.

[16] G. S. Rhodes. Low-speed wind-tunnel investigation of the static stability and control characteristics of an advanced turboprop configuration with the propellers placed over the tail. North Carolina State University, 1990. 